\title{
Review: Adrenal Insufficiency in Liver Disease
}

\section{Giuseppe Fede*, Luisa Spadaro and Francesco Purrello}

Department of Clinical and Molecular Biomedicine, University of Catania-Garibaldi Hospital, Catania, Italy

\begin{abstract}
Adrenal Insufficiency (AI), defined as deficient production or action of glucocorticoids resulting from either a structural damage of adrenal glands (primary adrenal insufficiency) or an impairment of the hypothalamic-pituitary axis (secondary adrenal disease), is being reported with increasing frequency in patients with liver disease, and some authors proposed the term "hepato-adrenal syndrome". The prevalence of Al in patients with liver disease varies widely according to the study population: critically ill patients (33-92\%), stable cirrhosis (31-60\%), or decompensated cirrhosis, such as variceal bleeding (30-48\%) and ascites (26-64\%). However there is no current consensus about diagnostic criteria to define $\mathrm{Al}$ in patients with liver disease, and its prognostic relevance in stable cirrhosis is still unclear.
\end{abstract}

Keywords: Adrenal insufficiency; Liver; Cirrhosis

\section{Introduction}

Adrenal Insufficiency (AI) is defined as deficient production or action of glucocorticoids resulting from either a structural damage of adrenal glands, namely "primary adrenal insufficiency", or an impairment of the hypothalamic-pituitary axis or "secondary adrenal disease" [1]. Primary AI is rare in general population, with an annual incidence of approximately 6/million adults/year and prevalence of 40 to 110 cases/million adults [2] and autoimmune diseases are the most frequent causes in developed countries. Long-term glucocorticoid therapy is the most frequent cause of secondary AI, however any process that impairs the ability of the hypothalamic-pituitary axis to secrete ACTH can cause secondary adrenal insufficiency (i.e. Pituitary or suprasellar tumors).

During critical illness (such as septic shock, severe communityacquired pneumonia, trauma, head injury, burns) $\mathrm{AI}$ is frequent, and is associated with a worse prognosis [3]. It has been described as Relative Adrenal Insufficiency (RAI), which is an inadequate glucocorticoid activity relative to the severity of illness.

Recently, $\mathrm{AI}$ is being reported with increasing frequency in patients with liver disease, and some authors proposed the term "hepato-adrenal syndrome" [4]. The prevalence of AI in patients with liver disease varies widely according to the study population: critically ill patients (33-92\%) [4-8], stable cirrhosis (31-60\%) [9-14] or decompensated cirrhosis, such as variceal bleeding (30-48-60\%) [15]. However there is no current consensus to define AI in liver disease.

\section{Diagnosis of Adrenal Insufficiency}

\section{Basal plasma cortisol}

Basal plasma cortisol could be the initial test to assess AI. A very low early morning (measured between 8.00-9.00 am, coinciding with the diurnal peak of secretion) basal cortisol (less than $138 \mathrm{nmol} / 1$ ) is highly suggestive of AI, but lacks sensitivity because most patients with adrenal insufficiency have cortisol levels exceeding this value, and dynamic tests needs to confirm the diagnosis [2].

\section{Basal ACTH levels}

Basal ACTH levels (measured between 8-9 am) may differentiate between primary and secondary AI. In primary AI these exceed $100 \mathrm{pg} /$ $\mathrm{ml}$ (22 pmol/l), however, normal plasma ACTH values do not rule out mild secondary AI [16].

\section{Insulin-induced hypoglycaemia test}

Insulin-Induced Hypoglycaemia Test has been considered the gold standard, but is now rarely used due to concerns about patient safety when inducing hypoglycaemia.

\section{Standard Synacthen Test (SST)}

Standard Synacthen Test (SST) is the standard test to assess AI. SST is performed at any time irrespective of fasting with blood samples at baseline, and 30 and 60 minutes after $250 \mu$ g of ACTH 1-24 (Synacthen") given intravenously or intramuscularly. A post-stimulation cortisol level $>550 \mathrm{nmol} / 1(20 \mu \mathrm{g} / \mathrm{dl})$ excludes primary AI [2].

\section{Low Dose Short Synacthen Test (LDSST)}

Low Dose Short Synacthen Test (LDSST) uses $1 \mu \mathrm{g}$ of synthetic ACTH 1-24 (Synacthen') given intravenously, with cortisol measured at baseline, and after 20 and $30 \mathrm{~min}$. The normal response is a plasma cortisol concentration $\geq 500 \mathrm{nmol} / 1(18 \mu \mathrm{g} / \mathrm{dl})$. LDSST is more sensitive than SST in patients without critical illness. However LDSST has not been validated in critically ill patients, or in acute hypothalamicpituitary disorders [17].

\section{Corticotrophin-Releasing Hormone (CRH) test}

Corticotrophin-Releasing Hormone (CRH) test differentiates primary from secondary AI. In primary AI high basal ACTH levels rise after CRH administration. In secondary AI the low ACTH levels do not respond to CRH. Low ACTH levels with a prolonged increase after CRH define hypothalamic disease [2].

*Corresponding author: Fede G, Department of Clinical and Molecular Biomedicine, University of Catania-Garibaldi Hospital, Via Palermo 636 95122 Catania, Italy, Tel: (+39) 095 7598702; Fax: 0039-095 7598401; E-mail: g_fede@tiscali.it

Received December 11, 2013; Accepted January 15, 2014; Published January 23, 2014

Citation: Fede G, Spadaro L, Purrello F (2014) Review: Adrenal Insufficiency in Liver Disease. J Liver 3: 146. doi:10.4172/2167-0889.1000146

Copyright: ( 2014 Fede G, et al. This is an open-access article distributed under the terms of the Creative Commons Attribution License, which permits unrestricted use, distribution, and reproduction in any medium, provided the original author and source are credited. 


\section{Current Evidence for Adrenal Insufficiency Associated with Liver Disease}

\section{Critically ill patients with liver disease (Table 1)}

First evidences for adrenal dysfunction associated with liver disease were found studying patients with acute liver injury or decompensation of chronic liver disease hospitalized in ICU setting.

Harry et al. [6] studied 45 consecutive patients with acute liver failure admitted to ICU: abnormal SST was found in 62\% (reference ranges from a healthy population). The increment and peak cortisol values were lower in patients with hemodynamic instability, or ventilator dependence, and those who died or underwent liver transplantation.

Marik et al. [4] used the LDSST to assess adrenal function in 340 patients with either acute or chronic decompensated liver disease, or immediately after liver transplantation or transplanted previously requiring intensive care. AI was found in 33\% fulminant hepatic failure, $66 \%$ chronic liver disease, $61 \%$ history of liver transplantation, and $92 \%$ recent liver transplantation (with a steroid-sparing immunosuppressive regimen). Low serum HDL cholesterol level was the only variable associated with AI. The authors proposed the term "hepato-adrenal syndrome" to describe the association between adrenal dysfunctions and liver disease. In another study, the same authors investigated the new onset of $\mathrm{AI}$ in 101 critically ill patients with acute or chronic liver disease without AI at admission, performing repeated LDSST tests: $16 \%$ developed AI at median of 3 days after initial testing. The only factor predicting AI was a low HDL level at admission $(\mathrm{p}<0.001)$ [18]. The authors suggested that low levels of HDL may be pathogenetically linked to the high incidence of AI in patients with liver disease, because HDL is the principal precursor for steroid biosynthesis in the adrenal gland [19].

In another study [7] SST was performed to assess adrenal function in 101 critically ill patients with cirrhosis and severe sepsis. AI was diagnosed in $52 \%$, and was associated with lower mean arterial pressure (60 vs. $75 \mathrm{mmHg}, \mathrm{p}<0.001)$, more required vasopressors ( $73 \%$ vs. $25 \%$, $\mathrm{p}<0.001)$, and increased hospital mortality rate ( $81 \%$ vs. $38 \%, \mathrm{p}<0.001)$. SST was also used to evaluate 25 consecutive patients with cirrhosis and septic shock [5]. The prevalence of AI was $68 \%$, and it was higher in advanced liver disease (Child C: $76 \%$ vs. Child B: $25 \%, p=0.08$ ).

The discrepancies in the prevalence of AI (51-66\%) shown in these studies may be due to differences in methodology and thresholds used to assess adrenal function. However these data show that AI in critically ill patients with liver disease is frequent and lead to a worse prognosis.

\section{Patients with stable cirrhosis and decompensated cirrhosis (Table 2)}

Several studies have shown a high prevalence of AI in not critically ill patients with cirrhosis, suggesting that AI is likely to be a feature of liver disease per se and not simply related to critical illness.

McDonald et al. [11] studied 38 patients with non-alcoholic liver disease and 40 healthy controls using both SST and IIT: compared with healthy controls, patients with liver disease had a $64 \%$ reduction in maximal increments of plasma cortisol after IIT and a 39\% reduction after SST (all $\mathrm{p}<0.0001$ ), peak cortisol was negatively related to the severity of liver disease (assessed by Child-Pugh scores). In another study [13], the CRH test was used to study the HPA axes in 52 male cirrhotic: adrenal dysfunction was found in $42 \%$ using ACTH plasma level increments (<twice baseline), and in 58\% using cortisol levels (peak value $<550 \mathrm{nmol} / \mathrm{l}$ or $<250 \mathrm{nmol} / \mathrm{l}$ increase). The HPA dysfunction was related to the severe liver disease, but was not influenced by aetiology of cirrhosis.

We investigated 101 patients with cirrhosis without infection or hemodynamic instability, using LDSST [9]. We found a high prevalence of AI $(38 \%)$, related to the severity of liver disease. Low levels of

\begin{tabular}{|c|c|c|c|}
\hline Authors & $\begin{array}{l}\text { N. of patients and type of liver } \\
\text { disease }\end{array}$ & Type of test performed and definition of Al & $\begin{array}{l}\text { Prevalence } \\
\text { of Al }\end{array}$ \\
\hline Tsai et al. [7] & Chronic liver disease+Sepsis: 101 & $\begin{array}{l}\text { SST: baseline cortisol }>414 \mathrm{nmol} / \mathrm{l} \text {, or cortisol increase }>250 \mathrm{nmol} / \mathrm{l} \text { if baseline value between } 414 \text { and } \\
918 \mathrm{nmol} / / \mathrm{l}\end{array}$ & $51 \%$ \\
\hline Harry et al. [6] & Acute Liver Failure: 45 & SST: baseline cortisol>250 nmol/L, cortisol increase $>250 \mathrm{nmol} / \mathrm{L}$, or peak cortisol>500 nmol/L & $62 \%$ \\
\hline Marik et al. [3] & $\begin{array}{l}\text { Fulminant hepatitis: } 24 \\
\text { Chronic liver disease: } 146 \\
\text { Recent LT : } 119 \\
\text { History LT: } 51\end{array}$ & $\begin{array}{l}\text { LDSST: random cortisol level }>552 \mathrm{nmol} / \mathrm{l} \text { in stressed patients (hypoxemic respiratory failure, shock, } \\
\text { or requiring vasopressors), or random cortisol level }>414 \mathrm{nmol} / \mathrm{l} \text { or peak cortisol }>552 \mathrm{nmol} / \mathrm{l} \text { in non- } \\
\text { stressed patients }\end{array}$ & $\begin{array}{l}66 \% \\
33 \% \\
92 \% \\
61 \%\end{array}$ \\
\hline $\begin{array}{l}\text { Fernandez et } \\
\text { al. [5] }\end{array}$ & Cirrhosis + Sepsis: 25 & $\begin{array}{l}\text { SST: baseline cortisol }>414 \mathrm{nmol} / / \text {, or cortisol increase }<250 \mathrm{nmol} / \mathrm{l} \\
\text { if baseline value between } 414 \text { and } 918 \mathrm{nmol} / \mathrm{l}\end{array}$ & $63 \%$ \\
\hline
\end{tabular}

SST: Short Synacthen Test; LDSST: Low-Dose Short Synacthen Test

Table 1: Adrenal Insufficiency (Al) in critically ill patients with liver disease.

\begin{tabular}{|c|c|c|c|}
\hline Authors & N. of patients with cirrhosis and aetiology & Type of test performed and definition of Al & $\begin{array}{l}\text { Prevalence } \\
\text { of Al (\%) }\end{array}$ \\
\hline McDonald et al. [11] & $\begin{array}{l}38 \text { non-alcoholic liver disease compared with } 40 \\
\text { healthy controls }\end{array}$ & $\begin{array}{l}\text { IIT: reduction in maximal increments of plasma cortisol } \\
\text { SST: reduction in maximal increments of plasma cortisol }\end{array}$ & $\begin{array}{l}64 \% \\
31 \%\end{array}$ \\
\hline Ziets et al. [13] & 52 cirrhotics: 36 alcoholic, 16 virus related & $\begin{array}{l}\mathrm{CRH} \text { : } \\
\text { a) rise of plasma } \mathrm{ACTH}<\text { twice the basaline; } \\
\text { b) peak cortisol value }<550 \mathrm{nmol} / \mathrm{l} \text { or an increase }<250 \mathrm{nmol} / \mathrm{l}\end{array}$ & $\begin{array}{l}42 \% \\
58 \%\end{array}$ \\
\hline Fede et al. [9] & $\begin{array}{l}101 \text { cirrhotics: } \\
29 \text { alcoholic; } 47 \text { viral; } 29 \text { other }\end{array}$ & $\begin{array}{l}\text { LDSST: a) peak serum cortisol< } 494 \mathrm{nmol} / \mathrm{l} \text {; } \\
\text { b) peak serum cortisol<442 } \mathrm{nmol} / \\
\text { c) delta cortisol< } 250 \mathrm{nmol} / /\end{array}$ & $\begin{array}{l}38 \% \\
29 \% \\
60 \%\end{array}$ \\
\hline Acevedo J et al. [20] & 143 non-critically ill patients with cirrhosis & $\begin{array}{l}\text { RAl was defined as a serum total cortisol increase }<9 \mu \mathrm{g} / \mathrm{dL} \text { after SST from basal } \\
\text { values }<35 \mu \mathrm{g} / \mathrm{dL}\end{array}$ & $26 \%$ \\
\hline
\end{tabular}

IIT: Insulin-Induced Hypoglycaemia Test; SST: Short Synacthen Test; LDSST: Low-Dose Short Synacthen Test; RAI: Relative Adrenal Insufficiency.

Table 2: Adrenal Insufficiency (Al) in patients with stable cirrhosis. 
morning basal cortisol (between 8.00-9.00 AM) were an independent risk factor for AI.

LDSST and SST were used in 20 patients with cirrhosis and variceal bleeding, 60 stable cirrhotics and 14 healthy volunteers [15]. The prevalence of AI was similar in bleeders and stable cirrhotics using SST, but with LDSST it was higher in bleeders ( $60 \%$ vs. $48 \%$; $\mathrm{p}=0.01)$. Furthermore, variceal bleeders had higher basal and peak cortisols than stable cirrhotic, but similar delta cortisol, demonstrating an inadequate adrenal response with respect to the severity of patient illness (critical illness-related corticosteroid insufficiency). AI was not associated with significant differences in clinical course/outcomes. Lastly, in a recent study assessing 143 non-critically ill patients with cirrhosis, low total delta cortisol values have been associated with higher incidence of severe sepsis, type 1 hepatorenal syndrome, and higher short-term mortality [20].

Despite discrepancies in the prevalence of AI amongst studies, due to different criteria to define AI, the data demonstrate adrenal dysfunction in patients with stable and decompensated cirrhosis, not only due to sepsis but also bleeding and ascites.

\section{Free cortisol vs. total cortisol measurement (Table 3)}

A relevant issue in the assessment of $\mathrm{AI}$ in cirrhosis is the measurement of total serum cortisol rather than serum free cortisol. Normally, $70 \%$ of circulating cortisol is bound to Corticosteroid Binding Globulin (CBG), $20 \%$ is bound to albumin, whereas the remaining $10 \%$ is free or unbound. Only the latter is the biologically active fraction [21]. In patients with liver disease low albumina and CBG concentrations may increase the percentage of free cortisol, thus the prevalence of AI is overestimates if adrenal function is assessed only using total cortisol measurement. This has been demonstrated in several studies.

Galbois et al. [10] used salivary cortisol as a marker of free cortisol concentration to assess adrenal function in 88 patients with cirrhosis: $33 \%$ had an abnormal total cortisol levels but only $9 \%$ had AI when salivary cortisol was considered. Ascites and low HDL levels were independent risk factors for AI. In another study both serum total and plasma free cortisol were used to study 43 clinically stable cirrhotic [12]. The prevalence of AI was $39 \%$ using standard criteria (peak total cortisol $<500 \mathrm{nmol} / \mathrm{L}$ ), $47 \%$ using Critical Illness-Related Corticosteroid Insufficiency (CIRCI) criteria (delta total cortisol $<250 \mathrm{nmol} / \mathrm{L}$ ), and $12 \%$ using free cortisol criteria (peak plasma free cortisol $<33 \mathrm{nmol} / \mathrm{L}$ ). The low prevalence of AI found using free cortisol or salivary cortisol rather than total cortisol; lead some authors to express concerns about the clinical relevance of AI associated with cirrhosis [22].
We recently studied 79 patients with stable cirrhosis using both total and free cortisol measurements: AI was diagnosed in $34 \%$ of patients using total cortisol and in 29\% using free cortisol [23]. Low concentrations of CBG mainly explained the discrepancy between the two cortisol assays. Moreover we evaluated the usefulness of estimated methods of free cortisol, i.e. calculated Free Cortisol (cFC) and Free Cortisol Index (FCI), which is the ratio between total cortisol and CBG concentration [24]. Measurements of $\mathrm{cFC}$ constantly overestimated free cortisol concentrations, with variations as large as $87 \%$. Conversely, FCI had a good level of agreement with free cortisol.

Thus, this latter study showed a high prevalence of adrenal dysfunction in patients with cirrhosis independently of cortisol assays (free or total cortisol), and the FCI as useful surrogate of free cortisol to assess adrenal function in patients with liver disease. However these findings need to be validated with further studies.

\section{Conclusion}

The literature suggests that $\mathrm{AI}$ in patients with liver disease is frequent both during acute critical illness (sepsis, shock and variceal bleeding) and during stable cirrhosis [4-7]. Liver disease per se may lead to progressive impaired of HPA axis [9]. However, there needs to be consensus on the appropriate tests and the accepted normal values to assess adrenal function in liver disease.

The clinical presentation of AI may be subtle in the absence of an adrenal crisis, with the gradual development of nonspecific symptoms such as fatigue, weakness, diffuse myalgia, weight loss, nausea, anorexia [25]. In stable cirrhosis adrenal insufficiency could be a sub-clinical condition triggered by acute events such as infections or other acute illness, leading to a worse prognosis [9]. Basal total cortisol should be routinely measured when AI is highly suspected, and if there are low basal cortisol levels an ACTH stimulation test should be performed, to identify patients with AI and eventually corticosteroid supplementation needs to be considered, albeit the lack of clear recommendation in this regard.

The mechanisms by which liver disease leads to AI are still unclear, but some hypotheses have been suggested (Figure 1). A decrease in total cholesterol, HDL cholesterol, and LDL cholesterol concentrations, frequent in cirrhosis [26], may lead to lack of substrates for steroidogenesis [19] and to a progressive exhaustion of adrenal reserve ("Adrenal-exhaustion syndrome") [18]. Furthermore, the increased levels of circulating endotoxin (e.g. lipopolysaccharide) and pro inflammatory cytokines (such as TNF- $\alpha$, IL-1, and IL-6) frequent during liver disease could impair the HPA axis [27].

\begin{tabular}{|c|c|c|c|}
\hline Authors & $\begin{array}{l}\text { No. of patients with cirrhosis and } \\
\text { aetiology }\end{array}$ & Type of test performed and definition of Al & $\mathrm{Al} \%$ \\
\hline Galbois et al [10] & 88 (ALD: 63, VIR: 63, ALD+VIR: 8, other: 4) & $\begin{array}{l}\text { SST } \\
\text { a) basal serum total cortisol }<250 \mathrm{nmol} / \mathrm{l} \text { or/and post-stimulation values }<494 \mathrm{nmol} / \mathrm{l} \text { or/and } \\
\text { increase values }<250 \mathrm{nmol} / \mathrm{l} \\
\text { b) basal salivary cortisol }<1.8 \mathrm{ng} / \mathrm{ml} \text { or/and post-stimulation values }<12.7 \mathrm{ng} / \mathrm{ml} \text { or/and increase } \\
\text { values }<3 \mathrm{ng} / \mathrm{ml}\end{array}$ & $\begin{array}{l}33 \% \\
9 \%\end{array}$ \\
\hline Tan et al. [12] & $\begin{array}{l}43 \text { (ALD: } 10, \text { VIR: } 11 \\
\text { ALD + HCV: } 8 \text {, PBC: } 3 \text {, PSC: } 4 \text {, NASH: } 4 \\
\text { Other: } 3 \text { ) } \\
10 \text { healthy volunteers }\end{array}$ & $\begin{array}{l}\text { SST } \\
\text { a) peak total cortisol }<500 \mathrm{nmol} / / \\
\text { b) delta total cortisol<250 nmol// } \\
\text { c) peak plasma free cortisol }<33 \mathrm{nmol} / \mathrm{l}\end{array}$ & $\begin{array}{l}39 \% \\
47 \% \\
12 \%\end{array}$ \\
\hline Fede et al. [9] & 79 (ALD: 44, VIR: 14, other: 21) & $\begin{array}{l}\text { LDSST } \\
\text { a) peak serum cortisol<494 } \mathrm{nmol} / \mathrm{l} \\
\text { b) peak free cortisol<33 nmol// } \\
\text { c) peak free cortisol<25 nmol/l }\end{array}$ & $\begin{array}{l}34 \% \\
28 \% \\
19 \%\end{array}$ \\
\hline
\end{tabular}

SST: Short Synacthen Test; LDSST: Low-Dose Short Synacthen Test.

Table 3: Adrenal Insufficiency (AI) in patients with cirrhosis using total cortisol, free cortisol and salivary cortisol. 


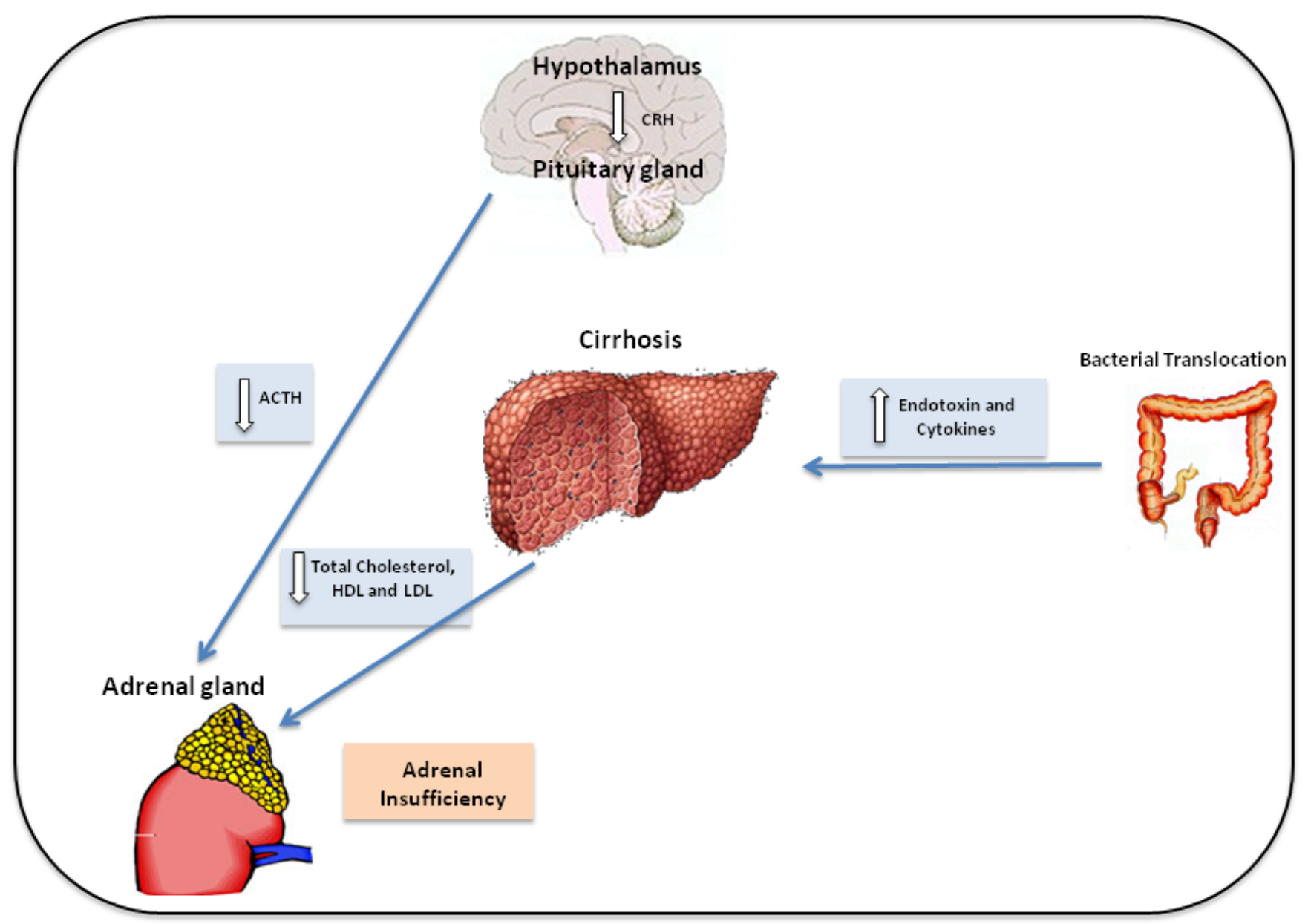

Figure 1: Possible causes of adrenal dysfunction in liver disease. ACTH: Adrenocorticotropic Hormone; CRH: Corticotropin-Releasing Hormone; HDL: High Density Lipoprotein.

Further studies are needed to clarify the clinical importance of AI associated to liver disease. Lastly, the effect of corticosteroid supplementation in patients with liver disease and acute decompensation or critical events should be assessed prospectively within randomized clinical trials.

\section{Contributorship Statement}

Fede Giuseppe: conception and design, acquisition of data, analysis and interpretation of data, drafting the article; Luisa Spadaro: revising the article critically for important intellectual content; Francesco Purrello: revising the article critically for important intellectual content.

\section{References}

1. Aron DC FJTJ (2007) Glucocorticoids and adrenal androgens. In: Gardner D.G. SD, editor. Greenspan's: Basic \& Clinical Endocrinology. (8thedn), New York, USA, 356-363.

2. Parker KL, Kovacs WJ (2002) Addison's disease (adrenal insufficiency). In: Wass JAH, Shalet SM, (eds.) Oxford Textbook of Endocrinology and Diabetes. (1stedn), Oxford, UK 837-844

3. Marik PE, Pastores SM, Annane D, Meduri GU, Sprung CL, et al. (2008) Recommendations for the diagnosis and management of corticosteroid insufficiency in critically ill adult patients: consensus statements from an international task force by the American College of Critical Care Medicine. Crit Care Med 36: 1937-1949.

4. Marik PE, Gayowski T, Starzl TE; Hepatic Cortisol Research and Adrenal
Pathophysiology Study Group (2005) The hepatoadrenal syndrome: a common yet unrecognized clinical condition. Crit Care Med 33: 1254-1259.

5. Fernández J, Escorsell A, Zabalza M, Felipe V, Navasa M, et al. (2006) Adrenal insufficiency in patients with cirrhosis and septic shock: Effect of treatment with hydrocortisone on survival. Hepatology 44: 1288-1295

6. Harry R, Auzinger G, Wendon J (2002) The clinical importance of adrenal insufficiency in acute hepatic dysfunction. Hepatology 36: 395-402.

7. Tsai MH, Peng YS, Chen YC, Liu NJ, Ho YP, et al. (2006) Adrenal insufficiency in patients with cirrhosis, severe sepsis and septic shock. Hepatology 43: 673681.

8. Arabi YM, Aljumah A, Dabbagh O, Tamim HM, Rishu AH, et al. (2010) Lowdose hydrocortisone in patients with cirrhosis and septic shock: a randomized controlled trial. CMAJ 182: 1971-1977.

9. Fede G, Spadaro L, Tomaselli T, Privitera G, Piro S, et al. (2011) Assessment of adrenocortical reserve in stable patients with cirrhosis. J Hepatol 54: 243250 .

10. Galbois A, Rudler M, Massard J, Fulla Y, Bennani A, et al. (2010) Assessment of adrenal function in cirrhotic patients: salivary cortisol should be preferred. J Hepatol 52: 839-845.

11. McDonald JA, Handelsman DJ, Dilworth $P$, Conway AJ, McCaughan GW (1993) Hypothalamic-pituitary adrenal function in end-stage non-alcoholic liver disease. J Gastroenterol Hepatol 8: 247-253.

12. Tan T, Chang L, Woodward A, McWhinney B, Galligan J, et al. (2010) Characterising adrenal function using directly measured plasma free cortisol in stable severe liver disease. J Hepatol 53: 841-848. 
13. Zietz B, Lock G, Plach B, Drobnik W, Grossmann J, et al. (2003) Dysfunction of the hypothalamic-pituitary-glandular axes and relation to Child-Pugh classification in male patients with alcoholic and virus-related cirrhosis. Eur $\mathrm{J}$ Gastroenterol Hepatol 15: 495-501.

14. Thevenot T, Dorin R, Monnet E, Qualls CR, Sapin R, et al. (2012) High serum levels of free cortisol indicate severity of cirrhosis in hemodynamically stable patients. J Gastroenterol Hepatol 27: 1596-1601.

15. Triantos CK, Marzigie M, Fede G, Michalaki M, Giannakopoulou D, et al. (2011) Critical illness-related corticosteroid insufficiency in patients with cirrhosis and variceal bleeding. Clin Gastroenterol Hepatol 9: 595-601.

16. Oelkers W (1996) Adrenal insufficiency. N Engl J Med 335: 1206-1212.

17. Kazlauskaite R, Evans AT, Villabona CV, Abdu TA, Ambrosi B, et al. (2008) Corticotropin tests for hypothalamic-pituitary- adrenal insufficiency: a metaanalysis. J Clin Endocrinol Metab 93: 4245-4253.

18. Marik PE (2006) Adrenal-exhaustion syndrome in patients with liver disease. Intensive Care Med 32: 275-280.

19. Yaguchi H, Tsutsumi K, Shimono K, Omura M, Sasano H, et al. (1998) Involvement of high density lipoprotein as substrate cholesterol for steroidogenesis by bovine adrenal fasciculo-reticularis cells. Life Sci 62: 13871395.

20. Acevedo J, Fernández J, Prado V, Silva A, Castro M, et al. (2013) Relative adrenal insufficiency in decompensated cirrhosis: Relationship to short-term risk of severe sepsis, hepatorenal syndrome, and death. Hepatology.
21. Coolens JL, Van Baelen H, Heyns W (1987) Clinical use of unbound plasma cortisol as calculated from total cortisol and corticosteroid-binding globulin. J Steroid Biochem 26: 197-202.

22. Thevenot T, Borot S, Remy-Martin A, Sapin R, Penfornis A, et al. (2009) Assessing adrenal function in cirrhotic patients: is there a reliable test? Gastroenterol Clin Biol 33: 584-588.

23. Fede G, Spadaro L, Tomaselli T, Privitera G, Scicali R, et al. (2013) Comparison of Total Cortisol, Free Cortisol, and Surrogate Markers of Free Cortisol in Diagnosis of Adrenal Insufficiency in Patients With Stable Cirrhosis. Clin Gastroenterol Hepatol.

24. Vincent RP, Etogo-Asse FE, Dew T, Bernal W, Alaghband-Zadeh J, et al (2009) Serum total cortisol and free cortisol index give different information regarding the hypothalamus-pituitary-adrenal axis reserve in patients with liver impairment. Ann Clin Biochem 46: 505-507.

25. Nieman LK (2012) Diagnosis of adrenal insufficiency in adults.

26. Cicognani C, Malavolti M, Morselli-Labate AM, Zamboni L, Sama C, et al (1997) Serum lipid and lipoprotein patterns in patients with liver cirrhosis and chronic active hepatitis. Arch Intern Med 157: 792-796.

27. Bornstein SR (2009) Predisposing factors for adrenal insufficiency. N Engl J Med 360: 2328-2339. 